\title{
The Influence of People's Practices and Beliefs on Conservation: A Case Study on Human-Carnivore Relationships from the Multiple Use Buffer Zone of the Panna Tiger Reserve, India
}

\author{
S. S. Kolipaka*, G. A. Persoon, H. H. de Iongh and D. P. Srivastava \\ Institute of Cultural Anthropology and Developmental Sociology, Leiden University, \\ Leiden, The Netherlands \\ *E-mail: kolipaka.s.s@gmail.com
}

\begin{abstract}
KEYWORDS Human-Carnivore Interactions. Human-Wildlife Conflicts. Tolerance. Intrinsic Values. Norms. Non-monitory Motivators. Coexistence. Carnivores. Tigers. Social Factors

ABSTRACT The case presented in this paper is a unique situation of livestock pastoralists, living in the buffer zone of Panna Tiger Reserve in India, displaying unusually high tolerance towards large carnivores in spite of frequent predation incidents. The researchers dissect the case, examine local people's practices anddraw attention to factors influencing peoples practices.Through interviews and personal observations the researchers collected detailed information on peoples practices and the factors influencing such practices. They collected information on large carnivores near 29 villages in the buffer zone and looked at factors influencing their presence in these areas. Their findings reveal the play and working of several social factors that are instrumental in influencing peoples tolerance and people's behaviours towards forests and wildlife and recommend that carnivore conservation projects focusing outside protected areas should critically assess the influence of such aspects on their conservation goals. And wherever applicable, find ways to innovatively model them into their conservation plans.
\end{abstract}

\section{INTRODUCTION}

In India and other parts of the world, wildlife species are known to frequently move beyond the boundaries of protected areas and persist in multiple use forestlands, private lands and human dominated landscapes. Generally, these areas are under a variety of human land uses and accommodate village settlements and people's activities like livestock grazing, agriculture and also their recreation. It is widely accepted that when humans share space with wildlife, interactions are inevitable and some interactions have negative consequences for humans and for wildlife. Fearing conflicts and eventually loss of people support for conserving wildlife outside protected areas there is a growing interest within conservation planners and practitioners to understand correlates that promote coexistence of people and wildlife. Examples include promoting coexistence in conservation plans for tigers and leopards in India, Jaguars in South America and wolves and bears in Europe (Wikramanay-

Address for correspondence::

S.S. Kolipaka

Kamerlingh Onneslaan 6

2641 ZN, Pijnacker, Netherlands ake et al. 2011; Chapron et al. 2014; Odden et al. 2014; Rabinowitz 2014).

Conserving wildlife outside protected areas especially endangered large carnivores like tiger, wolf and bear has always posed challenges. This is because large carnivores are known to attack people, create economic losses through predation on livestock, in some situations they are culturally undesirable, and some species also trigger fear within people (Athreya et al. 2013; Chapron et al. 2014; Goodale et al. 2015). People are known to respond to these physical and psychological threats by retaliating on carnivores and carnivore conservation promoters. Human caused mortality of carnivores through direct killing of carnivores, keeping a blind eye to their poaching or decreasing support for their conservation are all reasoned to their decline globally (Wikramanayake et al. 2011; Inskip et al. 2013; Traves and Bruskotter 2014; Rabinowitz 2014; Madhusudan 2015). Dissimilar to the above situations, there are also documented cases where local people show much restrain and tolerate large carnivores in spite of the threats they pose to human interests, allowing coexistence (Jones et al. 2008; Chapron et al. 2014; Goodale et al. 2015; Vucetich et al. 2015). 
Since humans and their activities are inseparable features of the landscape outside protected areas, knowledge of the factors that enable coexistence of people and carnivores are always interesting to conservation planners. Literature on the subject of human-carnivore interactions indicates that people's tolerance of carnivores is a vital ingredient for carnivore survival outside protected areas (Traves and Bruskotter 2014; Yirga et al. 2014). However, the factors motivating people's tolerance of carnivores are numerous and range from monitory factors to case specific contextual factors to social factors (Banerjee et al. 2013; Chapron et al. 2014; Traves and Bruskotter 2014). Further, it is also recognized that the factors influencing people's tolerance of carnivores are not straightforward but many, interrelated and whose functions and relationships are complex and not fully understood (Traves and Bruskotter 2014; Goodale et al. 2015).

To further improve existing knowledge and understanding on the topic of human motivations to tolerate carnivores and also to elaborate on the interrelatedness and complexity of factors affecting human tolerance of carnivores, the researchers critically examined a case study of livestock pastoralists from the multiple use buffer zone of Panna Tiger Reserve. Uniquely, the pastoralists do not retaliate on large carnivores such as the tiger (Panthera tigris), leopard (Panthera pardus), grey wolf (Canis lupus) or sloth bears (Melursus ursinus) in spite of recurring livestock losses and threat of personal injury. Initial enquiries into this unique case revealed the existence and play of several social factors such as culturally grounded practices, their religious beliefs and norms influencing their livestock management practices and views on carnivores. Based on these initial cues the researchers set the focus and objectives to:

1. Examine and describe local livestock management practices drawing attention to factors influencing these practices.

2. Describe qualitatively the relationship between the factors and pastoralists tolerance of carnivores.

3. To analyze the sustainability of those factors exerting influence.

The researchers believe that such detailed dissection of a positive case of tolerance will improve the understanding on the nature and depth of influence of social factors on carnivore conservation outside protected areas.

\section{METHODS}

Data presented in this paper is collected over a four-year period between 2010 and 2014. A large amount of data was collected by the principal researcher, as part of his project to study tiger conservation in multiple use forests of India and unpublished information relevant for this paper is used from the same data set.

\section{Study Area}

This research work was carried out in the multiple use buffer zone forests of Panna Tiger Reserve in India (Fig. 1) located in north central Madhya Pradesh at longitude $79^{\circ} 556 \mathrm{E}$ to $80^{\circ} 273 \mathrm{E}$ and latitude $24^{\circ} 274 \mathrm{~N}$ to $24^{\circ} 905 \mathrm{~N}$. The tiger reserve is spread over an area of approximately $1400 \mathrm{~km}^{2}$, of which approximately $550 \mathrm{~km}^{2}$ is demarcated as an in-violate core zone, where human activity is restricted and natural resource extraction is prohibited. The remaining $850 \mathrm{~km}^{2}$ is a multiple use buffer zone, where local people have traditional rights called Nistar to extract forest resources.

The area has tropical climate with three distinct seasons. The hot summers are between March and June, wet season from July to October and the mild winter season from November to February. The annual rainfall is approximately $1100 \mathrm{~mm}$. Monsoon rains are the only source of water for large areas of the park. The maximum day temperatures in summer reach $47^{\circ} \mathrm{C}$ and in winters the temperature can drop to $3^{\circ} \mathrm{C}$ during nights. Influenced by cyclones on the coasts, a few winter and summer showers are common in the study area (Mathai 1999). The terrain in the study area can be best described as hilly with flat plateaus and plains areas.

\section{Local People Communities}

A total of 42 villages with an estimated human population of 43,125 people live within the multiple use buffer zone of the Panna Tiger Reserve. Tens of villages are also located outside the periphery of the buffer zone. Extremely low levels of socioeconomic development characterize people in the area (Mathai 1999). Education and modern skills amongst local people are very low making their chances of employment almost non-existent. Cattle rearing and agricul- 


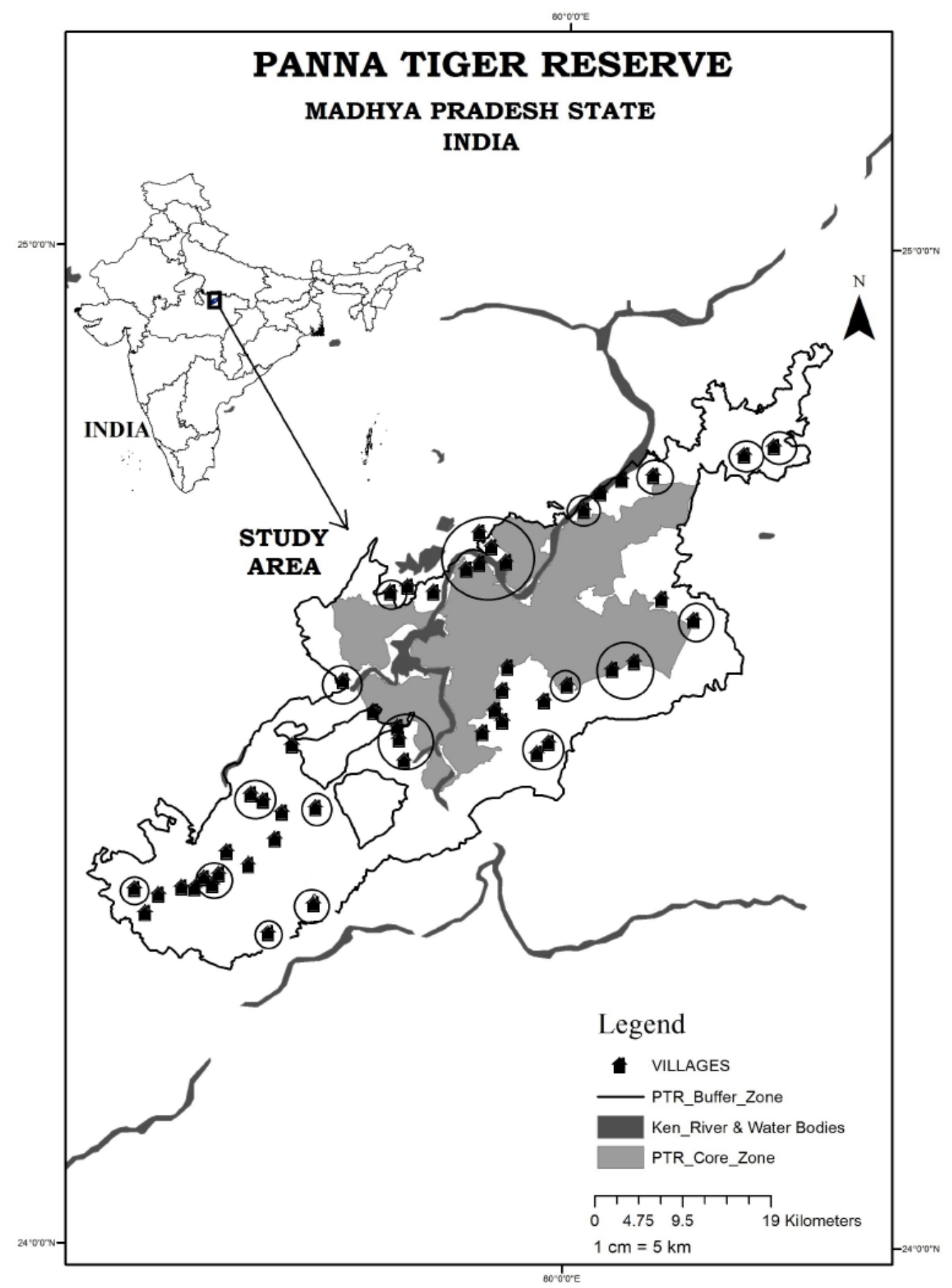

Fig. 1. The dark area is the involate ore zone and the adjoining aeas with villages is the multiple use buffer zone of Panna Tiger Reserve. Data for this study was collected only from those villages with circles around them. 
ture are common but only provide subsistence occupations for a majority of the local people. Working, as daily wage laborers, collecting and selling fuel wood and non-timber forest products are important sources of income for a substantial number of people. Due to rapid increase in local population and division of lands across generations (father to son), most landholdings are small and are used exclusively for agriculture (Mathai 1999).

The major ethnic groups of the area are the Gonds (Rajgonds, Nandgonds and Saurgonds) and Khairuas among the tribes and the Yadavs among the non-tribal (Mathai 1999). People representing 30 jati's (caste or tribe) are described in the study area. People typically live in mixed community villages with Hindu jati, adivasi (original inhabitant) and Muslim jati, people living together. There are also a few small forest villages, where all residents belong to a single jati. Local traditional practices such as worship of animistic spirits are actively practiced and reflect in day-to-day life of local people in the study area. It is also common to see members from different jati's following comparable practices or having overlapping beliefs.

\section{Carnivores in the Study Area}

Over twenty terrestrial mammalian carnivores are recorded in Panna Tiger Reserve core and buffer zones. Large terrestrial carnivores (>20kg body weight) include the tiger (Panthera tigris tigris), leopard (Panthera pardus fusca), Indian wild dog or dhole (Cuon alpinus), wolf (Canis lupus pallipes), striped hyena (Hyaena hyaena), sloth bear (Melursus ursinus) and domestic dogs (Canis lupus familiaris).

\section{Selection of Villages and Informants}

The researchers wanted to include villages and people with varying geographic and demographic features in the final sample. Further, they wanted to collect information, which could be quantitatively and qualitatively analyzed and support the key research objectives. Distance from core zone to the villages and size of the village were two criteria's the researchers used and selected 29 out of the 42 villages located within the buffer zone (Fig. 1). Five to ten house- holds from each of the shortlisted villages were selectively sampled and a total of 255 households were finally interviewed. The researchers ensured that the interviewed households represented members from the diverse jatis in the villages, ensured that households keeping the three livestock types were included and also ensured that households who earned a livelihood from livestock and those who kept livestock purely for subsistence were also included.

\section{Data Collection}

To study the influence of local practices on large carnivores, the researchers focused on two livestock management practices: 1) Villagers practice of disposing dead cattle carcasses, and 2) Villagers practice of abandoning unwanted livestock. To establish the number of livestock carcasses near villages the researchers maintained records of cattle carcasses dumped outside, and the 29 villages included in the study for the whole of 2013. The researchers selectively set up photo camera traps (10 Cuddy-Back white flash photo camera traps) near carcasses to record presence of carnivores. To establish numbers of livestock killed by large carnivores, the researchers collected information on livestock losses from villagers (part of interviews) and also analyzed records of livestock kills made by eight radiocollared tigers monitored by reserve staffs. To establish presence of carnivores around villages and in the buffer zone forests of the study area, the researchers incorporated relevant questions in the interviews and collected secondary information from villagers. The researchers crossed checked this information with detailed information collected by the principal researcher as part of his carnivore surveys in the region. All the collected information was collated and analyzed to established links between availability of carcasses and presence of carnivores near villages.

To examine factors influencing people's perceptions of risk from carnivore's, questions relating to households socioeconomics, yearly livestock losses, perceptions and attitudes towards carnivores and park management, knowledge on carnivores, herding and corralling strategies were incorporated into the interviews and analyzed. The researchers also made personal 
observations on 20 pastoralists by accompanying them on their day trips into the forests and kept notes of their behavior at spirit sites, responses to carnivores, herding techniques and other aspects. Information from interviews and observations were collated and analyzed to make meaning of pastoralists' perceptions of risk from carnivores and the same information was also used to assess interviewed pastoralists' adherence of religious norms, a social factor.

To collect information on the factors that influenced local livestock management practices, the researchers selectively framed questions and asked them during the informal interviews. As a first step, the questions were tested randomly on a few villagers. The collected information suggested that villagers linked their religious beliefs, cultural norms and aspects like convenience, and justified it to their practices. The researchers incorporated the different views in the final semi-structured interviews and informally interviewed 82 pastoralist households (out of the 255). Questions were designed to gather information on three main themes: 1) Local people's beliefs and norms towards the natural world, 2) benefits people derived as a result of their beliefs and norms, and 3) adherence and sustainability of existing practices. Interviews were informally conducted at homes of pastoralists and the checklist of themes ensured that all the topics and questions were covered. Information on sustainability was crosschecked with six spirit intermediaries on trends in continuity and erosion of beliefs.

The researchers noticed that people from lower ranking social classes (jatis) found it difficult to answer questions related to abandoning cattle or talking about presence of carcasses especially when there were onlookers from higher ranking jati's. So the researchers ensured that onlookers were not present while questioning households and also mixed sensitive topics into informal conversations.

\section{Analysis}

Qualitative data and quantitative data were separately analyzed but combined to interpret and support arguments made in the discussion. The Thematic Content Analysis as explained by Bernard (2006) was used to analyze the qualitative interviews. The informants' responses such as their views and perceptions on the core topics were placed into predefined themes under each of the core topics. This ensured that the focus stayed on the core topics (practices, religious beliefs, cultural norms, and adherence). This also helped keep focus on the research objectives. Individual statements were given codes and some of them were quoted directly in the papers' text. Themes were linked and suitable quotes were selected to suit the thematic structure of the paper and explained. Quantitative information from carnivore data was analyzed using a Microsoft Excel 2013 spreadsheet and presented in the paper. (See Table1: The methods employed in this study to collect information).

\section{RESULTS}

\section{Local Livestock Management Practices}

The researchers present two local livestock management practices and show evidence of how the local practice are deeply entrenched in complex local culture and also how they also provide practical advantages to carnivores.

Table 1: Summary of methods

\begin{tabular}{llllc}
\hline S. No. & Methods & Source & Sample & Period \\
\hline 1 & Observations & Livestock pastoralists 1 & 20 & 2013 \\
2 & Semi-structured Interviews & Households owning livestock & 82 & 6 \\
& & Spirit mediums & $2013-2014$ \\
3 & Pre-structured Questionnaire Survey & Households owning livestock & 255 & 2013 to 014 \\
4 & Counts of Livestock Kills & Panna Tiger Reserve records & 8 radio & 2010 to 2014 \\
5 & Carcass Counts & Collared tigers & 29 sites & $2013-2014$ \\
6 & Presence/ Absence Surveys & Buffer zone & N.A & $2012-2014$ \\
\hline
\end{tabular}

(1) Livestock pastoralists are those villagers who earn their livelihood from rearing livestock. 


\section{Practice 1: The Disposing of Dead Cattle Carcasses Near Village-Forest Fringes}

Most villagers in the study area viewed cattle as religious symbols and considered it a taboo to eat beef. Intentionally harming cows, killing or trading in their skins was also considered a taboo and people abstained from such activities. Even Muslims who generally had no religious taboo towards eating beef agreed to the views of the majority villagers and abstained from eating beef or trading in their skins in the study area.

In response to a question of how members from Muslim communities viewed cows and buffalos, a Muslim pastoralist replied, "Muslims in this area stopped eating beef nearly 30 years ago. Not even buffalos. Beef is only available in Mahoba, which is 40 kilometers from here".

As a social norm, most interviewed villagers regarded touching dead animals as unclean or achuut (not to touch) and normally abstained from such acts. Instead, they depended on a traditional system, where in members from the chamar jati (tanner) handled and removed dead animals from villages. Chamars are considered very low jati (status group) and treated as untouchables in the study area. Their houses within a village are usually located at a distance from homes of other villagers and villagers do not accept drinking water or food from Chamars. These low social groups of villagers earn livelihoods by performing menial jobs. They operate in villages on locally agreeable conditions, in some villages they pay an annual fee to the village panchayat (administrative body) for removing carcasses, while in some they are paid and in others they perform a free service without any monetary transaction involved. Chamars pick up cattle carcasses, skin them and dispose remains at village-forest fringes. After the flesh from dead carcasses is scavenged by animals and birds, chamars also remove bones and supply them to the bone meal industry. Where chamars are not available, villagers personally remove carcasses and dispose whole carcasses far from human habitation. The interviewed chamars in the study area report increasing objections from local villagers to skin and trade in skins of dead animals following a statewide ban on beef products. The current practice of disposing carcasses near village-forest fringes is widely accepted by all social groups in the area and it is also adhered in areas adjoining the study area.
Villagers from the forty two (42) villages in the study area keep over 45,000 cattle. In the 29 surveyed villages 20,968 livestock (cows, buffalos and goats) were counted and villagers reported losses of 6.9 percent or 1455 livestock in 12 months of 2013. Parallel to this, the researchers also counted 209 cattle carcasses (cows 172, buffalo 16 and 21 full or partial skeletons) in varying stages of decomposition in the multiple use forests of Panna Tiger Reserve between September 2013 and August 2014. According to villagers, a certain number of cattle perish annually for various reasons. Disease, shortage of forage and water, and natural causes are reasoned as major killers and accounted for mortalities of forty-three percent of dead cows, (53\%) fiftythree percent of buffalos and (55\%) fifty-five percent of goats. Predation by carnivores accounts for losses of (43\%) forty-three percent of dead cows, (32\%) thirty-two percent of buffalos and (33\%) thirty-three percent of goats. Villagers dispose dead carcasses near village-forest fringes and many carnivore species feed on these readily available carcasses.

Mortality of livestock reportedly occurs throughout the year with peak mortality occurring during summers and during the monsoon periods. During the hot summer months (April to June), livestock mortalities occur due to shortages in forage, exposure to the sun and water scarcity. While predation by carnivores and disease related losses are highest during monsoon period (July to October).

Presences of at least two species of large carnivores were recorded within a $1.5 \mathrm{~km}$ periphery of each of the 29 surveyed villages suggesting that large carnivores were active near and around human settlements. The carnivore surveys indicate that large carnivores have a wide distribution in the Panna Tiger Reserve Buffer zone, in spite of severe degradation of habitat and presence of humans in the area. Distribution varied from species to specie with the hyena, jackal and sloth bear having the widest and most uniform distribution in the multiple use forests while the tiger, leopard, wolf, and dhole distribution was restricted to specific areas. Domestic dog presence was very commonly recorded in the study area and they made forays deep into the forests during day but retreated towards the village-forest fringes by nightfall, where they were very active. The evidence of all carnivores species (except sloth bears) feeding on cattle 
carcasses near village-forest fringes and in the multiple use forests strengthens the argument of links between the practice of dumping carcasses and use of such cattle carcasses by carnivores.

\section{Practice 2: The Abandoning of Unwanted Cattle}

Eighty percent (80\%) of all households in the 29 surveyed villages owned cows. Majority of villagers kept cows for subsistence (milk and butter) and a few managed larger herds to earn a livelihood. However, buffalos and goats were maintained with an aim to earn a livelihood. Interviewed villages expressed both personal and social obligation to follow religious sanctions and social norms prohibiting sale of cows to slaughterhouses, selling their skins or eating beef. For most villagers, performing acts against their religious beliefs was personally confronting and they feared supernatural retribution and community disapproval.

Interviewed villagers revealed that they sometimes feel burdened to maintain excess and unwanted cows (as they cannot sell them to slaughterhouses) and voiced discontent on the increasing numbers of such cattle in the villages. They expressed that they need help to decrease cattle numbers but at the same time they vented helplessness in confronting the religious and social sanctions. Most interviewed villagers did not have answers when questioned about ways to control cow numbers. None of the interviewed villagers expressed willingness to take independent initiatives and all expected the reserve management to find a solution. Not willing to maintain larger numbers of cows and forced by sanctions not to dispose them, villagers disown and allow cows that do not yielding milk, become old or sick and male calves to roam feral in the jungles of the study area.

The surveys reveal that feral cattle that moved in the multiple use areas are vulnerable to predation by large carnivores. Feral cows in the multiple use forests originated from various sources. Their owners left behind thousands of cows when 10 villages were relocated from within Panna Tiger Reserve between 1990 and 2013. Such abandoned cows roam feral in the jungles and also produce young. Villagers living on the fringes of the multiple use buffer zone forests and those living insider the buffer zone too abandon their unwanted cattle and allow them to roam feral. Further, villagers who cannot afford the services of a baredi (community herder) allow cows to graze free, without herders, and such cattle stray far into the multiple use areas. As a result, feral and free roaming cattle abound in the study area and such cattle fall frequent prey to large carnivores. Characteristically, of the 648 animals killed by 8 radio-collared tigers of Panna Tiger Reserve between 2010 and 2014, fifty one percent (51\%) are cattle (243 cow and 35 buffalo). Out of the 243 cows killed by tigers 112 were males, 78 were females and 53 were young animals. This finding suggests that large carnivores like tigers actively predate on cows roaming in the Panna Tiger Reserve. Further, thirty one percent (31\%), nineteen percent (19\%) and sixty one percent (61\%) of all livestock owners with cows, buffalows and goats interviewed during this study experienced incidents of predation by large carnivores during 2013. This suggests that livestock, which is cared for and maintained by villagers, are also vulnerable to predation along with free roaming and untended cattle.

\section{Religious Beliefs and Norms of Local People Towards the Natural World}

The researchers found evidence that the beliefs and cultural norms that people held towards the natural world also influenced and guided some of their behaviors towards the natural world including wild animals.

\section{Beliefs Towards the Natural World}

Interviewed villagers strongly believed that worshipping forest spirits and making pacts with them ensured their personal wellbeing. They also believed that it ensured the safety of their family and also their livestock. They believed that powerful forces (in streams, trees, rocks, animals, and sky) inhabit forests and that these forces can cause harm when they move through forests. For instance, a large branch of a tree may fall on their herd animals, or a sudden flash flood in the stream could drown a person, or a boulder may tumble out of the hillock and destroy everything in its path. Interviewed pastoralists believed that the spirits they worshipped have the power to safeguard them from the forces of the natural world. They therefore, made pacts with the spirits for their continued protection. For example, respondents were fully aware that 
large carnivores like tigers and wolves moved in the same forests that they also used. They were also conscious of the dangers that tigers and wolves could pose to their livestock. Yet, interviewed pastoralists choose to believe that as a result of the pacts they have with their spirit protectors, their spirit protectors exerted control on the natural world including the tiger and the wolf and ensure their safety. Most interviewed pastoralists also justified attacks and killings of livestock by tigers and wolves as acts sanctioned deliberately by spirits. They viewed such incidents as normal occurrences and reasoned that spirits were helping the carnivore survive. Some interviewed members justified attacks on humans as a punishment for wrongdoing. The below narratives capture the belief of a respondent.

"Tigers like humans also feel hungry. When hungry tigers make loud growls. Such growls are pleas to spirits to lead them to prey. Spirits then guide tigers to prey animals and permit them to make a kill. Tigers can never make kills without the support and permission of the spirits. " (A pujari, a spirit ritual organizer)

Interviewed respondents believed that harming wildlife, even those that are potentially troublesome, was not their function. Yadav pastoralists for instance, revered the cow as their mother. Gond tribes viewed wild pigs, nilgai antelope, tiger amongst others as animals that were favorites to the forest spirits Siddh baba, Masan baba and Badami baba. They therefore, viewed the aforementioned animals belonged to the spirits and believed that harming them would result in retribution from the spirits. They also feared that hunting them would jeopardize their existing pacts with their spirit protectors, making them vulnerable to unforeseeable dangers. Some also believed that killing sacred animals would unleash retaliatory attacks by the animals upon them. Some respondents viewed that killing animals (such as the cow) that are sacred to some groups of people would lead to conflicts within people. For example, interviewed Muslim goat pastoralists disclosed that they stopped eating beef in their areas since the Hindus living there viewed the cow as a sacred animal. Similarly, the Hindu living in the area mutually respected the beliefs and values of muslim community members. Interviewed people expressed that they chose to make collective decisions on sensitive issues and did not make independent decisions.
They instead deliberated on the situation over a spirit ritual, consulted elderly members from their community and explored ways that were acceptable to majority of community members. The below narratives highlight the views and beliefs that respondents held towards animals.

"Badami baba is a very powerful forest spirit. Badami baba can summon the tiger by its ear. If a tiger repeatedly kills cattle or creates panic in villages, Badami baba can be requested to summon and tame the tiger." (A buffalo herder)

"Wolves should not be killed or harmed. Other wolves will unleash retaliatory attacks if their members are killed or attacked." (A Gond goat herder)

"Cows are holy animals and should not be harmed, killed or sold to slaughterhouses. Killing cows or selling their skins is therefore prohibited in the community and even evokes community disapproval and punishment on offenders. I fear my family and I may be face community exclusion if I supplied your project with buffalo calves or cow calves as bait to catch Tigers." (A Yadav pastoralist)

"The wild animals belong to the forest and it's the responsibility of the forest department personnel to control their animals. I am not going to kill them or harm them and evoke the department's wrath."

Influenced by the various cultural, popular and widely established beliefs, respondents abstained from harming or killing even bothersome animals.

Most interviewed pastoralists adhered to the religious and cultural norms that also had practical advantages to them. Adherence reduced risk of direct encounters with animals and discouraged risk taking that could jeopardize a pastoralist's safety and wellbeing.

\section{Religious Norms and Taboo Towards Animals}

Pastoralists adhered to many types of cultural norms and taboos that guided their behavior towards the natural world and the animals in the study area. For instance, a goat herder disclosed that as a norm he did not venture out into the forests at nighttime. He believed that forces of the forests, that which could potentially harm are most active during the dark hours. So he avoided venturing into the forests during the 
dark hours and waited till daybreak to take animals into the forests. He also returned home from the forest before it got dark. Most pastoralists as a general rule followed this norm. By adhering to such a norm directly translates into a positive advantage to those who adhere, meaning, those respondents adhering to the abovementioned norm avoid forays into the forests in the crepuscular (dawn and dusk) and nocturnal hours when most carnivores are active and visibility in the forest is minimum. By adhering to the norm, respondents are knowingly or unknowingly minimizing their risk of encountering animals or other dangers that lurk in dark in forests.

Another social norm commonly adhered by Yadav pastoralists demanded that cattle and pregnant animals should not be left to stay on their own in the forests. Such a situation would automatically allow spirits to summon tigers or other animals to predate on those animals. Therefore, if a situation arose, as a norm, the entire community took the responsibility to look for missing animals. Adherence to the above social norms has positive consequences for pastoralists. They gave extra attention and safeguarded pregnant and young animals and as a unit they collaboratively searched for lost and missing animals. Here, adhering to norms also reinforced collaboration amongst pastoralists and ensured community support if a person needed help thus reducing the risk of losing vulnerable animals to carnivores and even cattle thieves.

\section{Enforcement of Norms}

Traditional local institutions and self-regulation both ensured enforcement of norms amongst interviewed pastoralists. The researchers observed that young children were actively engaged in religious ceremonies from a young age. On special occasions they were also treated as gods and adults in turn worshipped children. One important and costly offering that villagers made to their spirit protectors as part of their pacts was to feed young girls (Kanya Bhoj), and this was regarded as esteemed offerings to spirits. In many ways, the children were introduced to local religious belief systems from an early age and mistakes made by children were normally overlooked and treated as acceptable. However, oversights by adults evoked within individuals, a fear of supernatural retribution or feelings of imminent damage from unknown sources. Sometimes the community imposed fines and even harsher community disapproval for breaking norms. Most respondents viewed that adhering to norms was normal behavior, it reduced dangers and kept spirits satisfied and therefore was to their own benefit. All interviewed religious intercessors $(n=6)$ reported observing an increasing trend in the numbers of villagers involved in the traditional belief system. They however felt that the younger generation, influenced by other worldly distractions, may temporarily lose interest in traditional beliefs but returned back to the traditional beliefs when they became adults.

\section{Perceptions About Risks From Carnivores}

The interviews revealed that the pastoralists' awareness and knowledge about wildlife was influenced by their own physical location, that is, areas in which they moved within the buffer zone. They had greater knowledge on animals that directly threatened them and their livestock (in real life and metaphorically), and those species that are easily visible than those that are cryptic, elusive or wholly nocturnal. For example, pastoralists herding goats and grazing on the flat plain areas of the buffer zone regard the wolf as a problem carnivore and report that it attacked their animals even in broad daylight. They however do not see the wolf as a threat to their own personal safety. The same goat herders revealed high familiarity with tigers (locally referred as Nahar and Sher) and leopards (Sher and Duranga) but they did not perceive them as threats to their animals or personal safety. Further, only forty six percent (46\%) of the interviewed pastoralists $(\mathrm{N}=255)$ could accurately identify tigers from leopards from photographs shown to them. An even smaller number could verbally describe differences accurately. A very small percentage of interviewed pastoralists (2\%) acknowledged seeing tigers or leopards in real life. The above information suggests that pastoralists had high awareness on animals like wolves that were present and posed direct problems to their livestock. However, they had little knowledge on cryptic carnivores like tigers and leopards, which are not easily visible and avoid open plains, where pastoralists frequent. These factors most likely ascribe to the difference in their knowledge on species. 
Based on interviews, the researchers assessed that a large majority of the interviewed (79\%) did not view tigers as a problem species. Only twenty one percent (21\%) of the pastoralists viewed tigers as a threat, of which nineteen percent $(19 \%)$ viewed them as threatening to large cattle. All pastoralists herding buffalos had high awareness about tigers, but only a small percentage (18\%) of them actually experienced loss from predation in 2013. The variations in perceptions of pastoralists on tigers are likely because of infrequent predation by tiger on buffalo. Tiger presence and distribution in the study area is restricted to certain patches of the multiple use buffer zone area (Fig. 1) and not the entire area. Hence, livestock losses from tigers were also restricted to some areas only and not experienced by all the pastoralists. Further, even within those areas with known tiger presence there were no incidents (historic or recent) of human deaths from tigers. The cryptic nature of tigers and the non-existent human fatalities from tigers may be the reason for the low one percent (1\%) fear amongst pastoralists that tigers would kill humans.

Forty four percent (44\%) of the interviewed pastoralists viewed leopards as threatening to large cattle and three percent (3\%) also felt that they were threatening to goats and cattle calves. Pastoralists did not see leopards as risk to human life. All (100\%) pastoralists with goats were familiar with wolves and seventy-one percent (71\%) of them viewed them as threatening to goats and cattle calves. A very small percentage (3\%) saw them as threatening to larger cattle and very few respondents (1\%) saw them as threatening to human life. Pastoralist's views suggest their high familiarity with some species and they readily see differences in the threat wolves and leopards pose to their safety and livestock. Pastoralists with goats also reported avoiding thickly vegetated forest patches fearing leopards and tigers and stuck to the open patches where visibility was greater. In some areas of the study, the pastoralists reported that wolves were locally extinct as a result of intense modification of open forest to suit agriculture.

Fifty two percent (52\%) of interviewed pastoralists viewed that sloth bears were dangerous to human safety as they attacked people and therefore the most threatening of all carnivores in the study area. However, at the same time forty seven percent (47\%) of interviewed pastoralists also did not view sloth bears as a threat. This difference in opinion is in spite of the wide distribution of sloth bears in the area. Attacks by bears on humans are not common in the study area but a few cases (8 in 2013) are reported every year. However, awareness about bears is high and so people are on vigil for bears when they move in forests. According to the pastoralists, bears are unpredictably aggressive when they have small cubs around them. Pastoralists did not see sloth bears as threatening to livestock but only to personal safety.

All interviewed pastoralists articulated deep knowledge on potential risks from individual large carnivores (tigers, leopards, wolves, sloth bears, jackals) to their personal safety and their livestock. Some interviewed pastoralists revealed specialized knowledge on some species resulting from their experiences. For instance, their familiarity with leopards was very unique, as they classed leopards into three different groups using a local reference system. This classification was based on leopard body size and the size and type of livestock they killed. These included, Duranga (a large male leopard capable of killing adult cattle), tenduva (smaller adult female leopards or young males that killed smaller cattle and calves) and cheetri (dog sized spotted cat that kills poultry and goats). All interviewed pastoralists were fully conscious that carnivores feed on carcasses dumped near villages and those in the multiple use forests. Very few $(1 \%)$ of the interviewed expressed fear of large carnivores to their personal safety. They reasoned that this was because there was enough wild prey for carnivores to eat in the forest including free roaming cattle. They also viewed that eating humans was not interesting to carnivores and were fully conscious that humans were no match for the strength of a tiger, leopard or a wolf. Pastoralists expressed that wolves were more easily visible and could be scared away by throwing stones and or by screaming. Ninety percent (90\%) of interviewed pastoralists viewed hyena and jackal as nonthreatening species. A small percentage of the interviewed pastoralists (16\%) viewed jackals as threat to personal safety.

The researchers' personal observations on pastoralists revealed that negative perceptions and attitudes of interviewed pastoralists towards carnivores did not translate into negative responses on carnivores. The researchers found 
no evidence to suggest that the pastoralists on whom they made detailed personal observations $(n=20)$ attempted to kill or consciously remove carnivores to decrease risk of predation on their livestock during the study period. All interviewed pastoralists viewed that occurrence of dangerous wildlife in the forests was normal and explicitly regarded harming or killing wildlife near spirit sites as a religious offence. The researchers found no evidence during the study to suggest that pastoralists broke commonly held norms. Figure 2 lists the pastoralists' views on carnivores based their perception of the species.

\section{DISCUSSION}

\section{Significance of Local Practices to Carnivore Conservation}

Results of this study indicate that local peoples practices have practical advantages for carnivore species.
In the multiple use buffer zone forests of Panna Tiger Reserve, the people's extractive activities especially fuel wood extraction and unchecked cattle grazing significantly reduce the quality of the habitat available for wild herbivores, which are natural prey for large carnivores. However, because of the widespread nature of local livestock management practices that include dumping of dead livestock carcasses, allowing unproductive cattle (old, sick and those that do not yield milk) and unwanted cattle (male calves and bulls) to roam feral, followed by poor corralling facilities for cows, and people's lenient cow herding strategies, large carnivores have access to readily available and continuous supply of alternative food sources in the buffer zone. Large carnivores are recorded feeding on such food sources in the Panna buffer zone. The researchers claim that the local people's livestock management practices are one of key governing factors influencing the presence and wide distribution of large carnivore species throughout the multiuse buffer zone and near villages. Va-

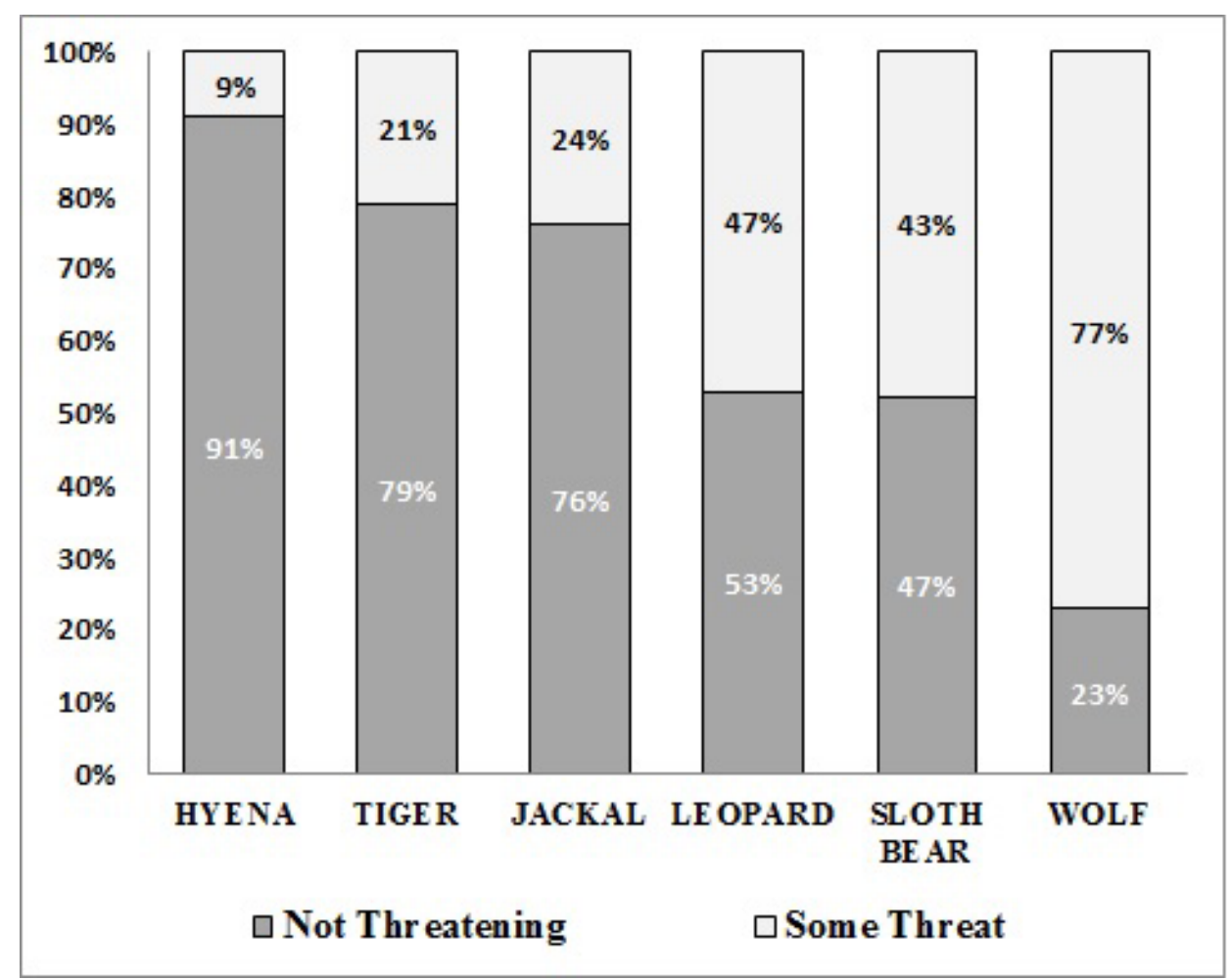

Fig. 2. The dark grey areas represents those who do not view carnivores in the study as a threat. The areas in white represent those who see a degree of threat from the species. 
leix et al. (2012) report of observing similar behavioral adjustments and adaptations by their study lions in Africa to feral cattle movements. Lions reportedly move more frequently into areas where feral cattle occur. Yirga et al. (2012) also report a similar case of hyenas adapting to human food sources and coexisting alongside people in Ethiopia, and Athreya et al. (2013) report of leopards adapting and thriving in large swaths of sugarcane fields with no natural forests in the vicinity, in Maharashtra state of India. The researchers suggest that large carnivores in Panna buffer zone too are displaying similar adaptability to living in the buffer zone by taking advantage of the prevailing human conditions such as, low direct retaliation by people, lenient livestock management practices and readily available food sources in the buffer zone.

While the above illustrates how some people practices have positive outcomes for large carnivores and also the ability of some large carnivore species to take advantage of peoples practices, the findings also reveal that pastoralists in Panna show high adaptability to living alongside large carnivores. Such adaptability to live along carnivores is driven by many, interlinked factors and each of the factors is elaborated to highlight its specific influence. For example, pastoralists feel reassured by their faith in their spirit protectors and experience a sense of security from powerful forces in the forests including wild animals. Nelson, Singh, Vucetich, Woodhouse and many others have reported this motivating function of religious beliefs on believers and that such belief systems are commonly practiced, even today, in many traditional societies across the world (Nelson 1974; Singh 2012; Vucetich et al. 2015; Woodhouse et al. 2015). Further, pastoralists in Panna adhere to cultural and religious norms towards forests and wildlife that by coincidence or conscious design reduce direct human impacts and also interactions with wildlife. For example, fearing retaliatory attacks from spirit wolves pastoralists do not scheme to exterminate wolves they instead chase them away.

Another factor is the pastoralists' superior traditional ecological knowledge on wildlife and their habits and their awareness of the wide distribution of large carnivores in the buffer zone. Pastoralists are familiar with local wildlife from a very early age. They accompany their parents on herding trips and sometimes they are also given independent charge to guard livestock. Such knowledge and awareness about animals coupled with traditional norms that lower interactions between people and carnivores and their religious beliefs that provide psychological respite from the dangers of living alongside carnivores, all contribute to the feeling of lowered risk from carnivores, which is enabling the observed high tolerance of carnivores in Panna buffer zone. However, as cautioned by many researchers negative interaction with carnivores leading to loss of human or livestock losses exceeding tolerable limits could change the people's responses towards carnivores and may provoke unwarranted actions towards carnivores.

\section{Factors Influencing Tolerance of Pastoralists}

The findings suggest that pastoralists and livestock owners display high tolerance towards large carnivores in spite of the dangers carnivores pose to their personal safety and that of their livestock. The researchers explain the observed tolerance within pastoralists as an outcome of several internal and external factors that collectively (but not necessarily in equal proportions) exert their influence influencing people's beliefs, perceptions, attitudes, behaviors and their perceived risks from carnivores and ultimately their responses towards carnivores. Internal factors are explained as intrinsic benefits and practical advantages that pastoralists experience from their religious beliefs, by adhering to cultural norms and following traditional practices. External factors are those real time contextual experiences. For instance, a fatal animal attack on a human that is frequently recollected by villagers or a violent conflict with authorities (man-man conflicts) that is still fresh in the minds of people.

\section{Internal Factors}

Interviewed pastoralists disclosed several intrinsic benefits they experience from their religious beliefs and adhering to norms, which allow them to cope with stressful situations in their lives. For instance, on one occasion, a tiger killed a few buffalos belonging to a pastoralist. The pastoralist, when questioned, interpreted the event as a coordinated event that took place 
with the approval of higher order spirits. He did not blame the tiger but instead shriveled into a state of submission and blamed himself for allowing the buffalos to stray into the forest at nighttime and accepted the killing by the tiger as a coordinated event, directed by the supernatural. Pastoralists regard the tiger as a powerful beast symbol both in a real world sense and also as a metaphoric (spirit) that inhibits the forests and that, which can influence their life. As also reported by other researchers, pastoralists in Panna believe that their spirit protectors have the power to both ensure human wellbeing and also to punish them (Buchler et al. 1980; Boteroa et al. 2014; Sidky 2015). In the above-described incident, the pastoralist viewed the killing of his buffalos by the tiger as an incident directed by the supernatural, beyond the mortals' ability to control. He also viewed the event as a punishment for leaving buffalos over the night in the forests, which according to him was a breach of norms. Many researchers including Woodhouse and Singh, report observing people in their study areas constructing similar meanings to events, events that are formidable, and overwhelming (Singh 2012; Woodhouse et al. 2015). Pastoralists also viewed that events such as natural calamities, disease outbreaks, large predators and sometimes events that are difficult to comprehend are controlled by the supernatural. Many researchers including Woodhouse and Singh, report observing people in their study arreas constructing similar meanings to events, events that are formidable, and overwhelming (Singh 2012; Woodhouse et al. 2015).

Pastoralists in this study disclose experiencing personal benefits from their religious beliefs and norms. For instance, the economically poor pastoralists had no alternatives but to move and use forests for their livelihood in spite of knowing that dangerous wildlife roam the forests. According to them, their belief in their spirit protectors and the pacts they make with them for their safety creates a state of mind, where they experience feelings of decreased anxiety, loss of fear to travel alone in forests, and loss of fear from the forces of the forests. These feelings that pastoralists experience are intrinsic in nature and the interviewed could clearly verbalize these benefits. Existence of such intrinsic benefits from religious beliefs have been acknowledged and also reported by many scholars (Nelson 1974; Johnson 2005; Boteroa 2014; Goodale et al. 2015). The importance of these intrinsic benefits when they are perceived through the mental lenses of economically backward rural communities like those in the study area, where communities are exposed to vagaries of nature, face persistent threats and have little or no social security provided by the state, are profound. Interviewed pastoralists are internally aware of the benefits of adhering to their religious beliefs and following norms and also fear losing this security if they act against the beliefs or norms. The fear of retribution, also reported by several researchers, is likely holding pastoralists in the study area from taking actions that can jeopardize their relations with their spirit protectors (Buchler et al. 1980, Horne 2003; Jones et al. 2008; Boteroa et al. 2014; Woodhouse et al. 2015). Such actions consciously taken or unintentional sometimes are also known to have benefits to natural world (Jones et al. 2008; Dudley et al. 2009; Dominguez et al. 2010).

Interviewed pastoralists also consciously maintained favorable relations with the reserve authorities. They however viewed wildlife as the property of the reserve and hence its management their responsibility. On questioning them about their willingness to take actions against problem animals, they readily pointed fingers at the reserve authorities blaming them for not managing their carnivores efficiently and refused to take any personal initiatives. Here, the conflicts with authorities over animals and the loss of rights to herd animals, a material requirement for the pastoralists is most likely the underlying reason for their tolerance for carnivores.

\section{External Factors}

The study reveals that real life contextual events experienced by pastoralists also influence their views, perceptions and attitudes towards large carnivores. For instance, many interviewed pastoralists $(79 \%)$ do not view the tiger as a threat to human life. Many of them (51\%) instead viewed the sloth bear as a greater threat. These variations in risk attributed to different animals are likely because of the following reasons. In the Panna study area, there are no known records of tiger attacks on humans in the last 30 years. On the other hand, human injuries from sloth bear attacks are more common. Secondly, according to the interview data, very few villagers ever encountered a tiger in real life 
but people encounter bears more often and are known to frequent village fringes frequently to feed on fruits of domesticated trees. Thirdly, tiger distribution and presence is restricted to certain patches of the reserve area and not the entire reserve area. On the other hand, bears have a wider distribution than tigers. Lastly, tigers are more cryptic and difficult to encounter than bears. As also pointed out by Goodale et al. (2015), these real life encounters and negative experiences are most likely influencing the pastoralists' perception of higher risk from sloth bears to human life than from tigers.

The study also reveals that pastoralists have proficient knowledge of local carnivore species and their habits. The researchers also found links that such knowledge was greater on species that either threatened their livestock, their personal safety or those species that are visible. Pastoralists also consciously weighed and chose strategies that worked best to reduce livestock losses. For instance, pastoralists chatted in the evenings and discussed animal sightings and made travel plans. Pastoralists knew about wolves, they viewed wolves as a threat to goats and young cattle calves and they felt that wolves were not a threat to their personal safety. Personal observations also revealed that pastoralists were very knowledgeable about wolves and their habits and adopted strategies that minimized losses from wolves. For example, some pastoralists used dogs for early warning against wolf attacks. Some pastoralists were aware that tigers and leopards were more cryptic and less visible than wolves. Hence, they consciously avoided patches with dense vegetation and thus avoided tigers and leopards. As also pointed out by Traves and Burskotter (2014), the pastoralists' knowledge, their ability to find solutions and mitigate losses all contribute to shaping their tolerance of large carnivores.

The researchers also found evidence that pastoralists took calculated risks and tolerated some of the threats posed by carnivores. For instance, pastoralists were dependent on the multiple use forests for their livelihoods as there were no alternative grazing grounds in the vicinity. They therefore consciously weighed the practical benefits of using the government administered buffer zone forests and tolerated inconveniences from wildlife and avoided acts such as killing or injuring problem animals and restrained acts that could jeopardize their rights to use the areas. Such conscious decision-making by rural pastoralists was also observed by Banerjee et al (2013) in their study in Gujarat State of India.

\section{Adherence to Practices}

Observations on pastoralists suggests that their adherence to religious and cultural norms was both widespread and also sustainable. Interviewed pastoralists viewed that adherence was not imposed on to them but it was in the personal interest of individuals to adhere or choose not to adhere. Pastoralists viewed nonadherence resulting in two different outcomes. For example, breaking social norms such as killing selling religious symbols like cows to slaughterhouses had larger community level repercussions. In these contexts enforcement was through local institutions. Secondly, breaking norms grounded in individual belief were more individually confronting, and here enforcement was through self-regulation. As also observed and reported by many researchers, local people in the study area experienced an obligation to follow culturally acquired norms because people believed that their actions influenced their wellbeing (Horne 2003; Johnson 2005; Botero et al. 2014). Therefore, adherence of norms was in an individual's personal interest.

Pastoralists also experienced practical advantages from adhering to their religious, social and behavioral norms. For instance, a social norm discourages human presence in the forest areas after the jackals start howling (basically nighttime). Another social norm commonly adhered by pastoralists prohibits cattle to be left unguarded in forests at nighttime. Influenced by such norms people help each other find lost or missing cattle. Factually, people who follow these norms benefit from reduced interactions with dangerous wildlife (which are most active in the crepuscular and nocturnal hours), and community members share an obligation to help each other search for missing cattle or those that stray too far. Such direct practical benefits resulting from following social norms may be the reason behind the high adherence of norms observed within local communities in the study area. Such practical advantages, as also observed in studies by Horne, are most likely motivating people's self-regulation of norms (Horne 2003). One interviewed pastoralist's narrative is particular- 
ly relevant to showcase the extent to which local people think and construct meaning of the retaliatory powers of their spirit protectors.

"Hunting of wild animals in our area stopped a long time ago. The forest guards here are very strict and do not spare anybody who hunts wildlife. Even the Thakur community members (local elite class) stopped hunting pigs and deer as a result. May be it is the spirits in the form of forest guards who are protecting animals from being killed."

\section{CONCLUSION}

Assessing the people's practices outside protected areas is important for conservation managers because as reported in this paper, sometimes local practices may not necessarily be conscious acts of local people to safeguard wildlife but could have ancillary effects with positive or negative outcomes for conservation. Likewise, local belief systems and norms associated with spirit sites like prohibitions on hunting may appear irrelevant and inadequate if one looks at the small geographic size of the sites. However, the widely prevalent and locally acceptable practices, the vital locations of spirit sites near valuable resource points like sources of springs, near streams, and the high numbers of adherers of the belief system are significant for conservation and cannot be overlooked.

The research raises questions about the role of non-monitory motivators to solicit people's support for conservation. In countries like India, where religion and culture still continue to influence people's daily lives and practices, it would be futile to attempt change in local practices without considering the underlying mechanisms in which the practices are grounded. This is particularly relevant to conservation outside protected areas, a known complex endeavor. The study illustrates ways to dissect and clearly visualize the social factors that sometimes sustain scenarios like coexistence. However, clever and replicable ways to embed the findings into projects still remain unclear and will need work.

If policymakers in India were to take this study seriously, they might want to look at ways to collaborate with local level institutions and also involve local villagers and religious leaders on conservation projects. Building bridges with local communities and local institutions is very relevant because existing practices recorded in the study area are likely to stay in use at least for the medium term in spite of all the modernization taking place in India.

\section{RECOMMENDATIONS}

As a result of conducting this research, the researchers propose that addressing the human dimension aspects is an inseparable part of carnivore conservation in multiple use and human dominated landscapes. This means carnivore conservation in multiple use forests or human dominated areas necessitates the need for a robust understanding and expertise in dealing with the human dimension aspects.

Issues related to the human dimension of wildlife can have sociopolitical repercussions. Therefore, if managers do not have the means or expertise, sometimes just being aware of the situation is better than actually trying to do something that could have counterproductive outcomes. The fact that non-financial motivators also play a larger role in people's behavior towards carnivores does not mean known financial motivators like compensations should be ignored.

\section{ACKNOWLEDGEMENTS}

The researchers wholeheartedly thanks the Madhya Pradesh Forest Department, particularly Mr. Sreenivasa Murthy for allowing access to the more remote areas of the Panna Tiger Reserve and to interact with villagers. The researchers thank the para-ecologists Mr. Sushil Kumar and Mr. Shabbir Bhai without whose knowledge and contacts it would have been very difficult to access local communities and have meaningful discussions on the study topic.

\section{REFERENCES}

Athreya V, Odden MJ, Linnell JDC, Krishnaswamy J, Karanth KU 2013. Big cats in our backyards: Persistence of large carnivores in a human dominated landscape in India. Journal Plus ONE, 0057872.

Boteroa CA, Gardnerc B, Kirbyd KR, Bulbuliae J, Gavinf MC, Grayg RD 2014. The ecology of religious beliefs. Proceedings of the National Academy of Sciences, 111(47): 16784-16789.

Banerjee K, Jhala YV, Chauhan KS, Dave CV 2013. Living with lions: The economics of coexistence in the Gir Forests, India. Journal PLoS ONE, 8(1): c49457.

Bernard HR 2006. Research Methods in Anthropology. Lanham: Altamira Press. 
Buchler I, De Vos G, Diamond S, Godelier M, Gumperz J, Krader L, Schwimmer E 1980. People in Culture: A Survey of Cultural Anthropology. USA: J.F. Bergin Publishers.

Chapron G, Kaczensky P, Linnell JDC, Manuela von A, Huber $C$ et al. 2014. Recovery of large carnivores in Europe's modern human-dominated landscapes. Science, 346(6216): 1517-1519.

Dominguez P, Zorondo-Rodriguez F, Reyes-Garcia V 2010. Relationships between religious beliefs and mountain pasture uses: A case study in High Atlas Mountains of Marrakech, Morocco. Human Ecology, 38: 351-362.

Dudley N, Higgins-Zogib L, Mansourian S 2009. The links between protected areas, faiths, and sacred natural sites. Conservation Biology, 23: 568-577.

Goodale K, Parsons GJ, Sherren K 2015. The nature of the nuisance- damage or threat- determines how perceived monetary costs and cultural benefits influence farmer tolerance of wildlife. Diversity, 7(3): 318-341.

Horne C 2003. The internal enforcement of norms. European Sociological Review, 19(4): 335-343.

Inskip C, Ridout M, Fahad Z, Tully R, Barlow A et al. 2013. Human-Tiger conflict in context: Risks to lives and livelihoods in Bangladesh Sundarbans. $\mathrm{Hu}$ man Ecology, 41: 169-186.

Johnson DDP 2005. God's punishment and public goods: A test of the supernatural punishment hypothesis in 186 world cultures. Human Nature: An Interdisciplinary Biosocial Perspective 16(4): 410-446.

Jones JPG, Andria M, Hockley N 2008. The importance of taboos and social norms to conservation in Madagascar. Conservation Biology, 22(4): 976-986.

Madhusudan MD 2015. Conservation conflicts from livestock depredation and human attacks by tigers in India. In: SM Redpath, RJ Gutierrez, KA Wood, JC Youngh (Eds.): Conflicts in Conservation: Navigating Towards Solutions. Cambridge: Cambridge University Press, pp. 268-270.

Mathai MV 1999. Habitat Occupancy by Tiger Prey Species Across Anthropogenic Disturbance Regimes in Panna National Park, Madhya Pradesh, India. MSc Thesis, Unpublished, Rajkot: Saurashtra University.
Nelson LD 1974. Functions and dimensions of religion. Sociological Analysis, 35(4): 263-272.

Odden M, Athreya V, Rattan S, Linnell JDC 2014. Adaptable neighbours: Movement patterns of GPScollared leopards in human dominated landscapes in India, PLoS ONE, 9(11): c112044.

Rabinowitz A 2014. An Indomitable Beast: The Remarkable Journey of the Jaguar. Washington: Island Press, pp. 133-149.

Sidky H 2010. Ethnographic perspectives on differentiating shamans from other ritual intercessors. Asian Ethnology, 69(2): 213-240.

Singh B 2012. The headless horseman of Central India: Sovereignty at varying thresholds of life. Cultural Anthropology, 27(2): 383-407.

Traves A, Bruskotter J 2014. Tolerance for predatory wildlife. Science, 344: 476.

Valeix M, Hemson G, Loveridge AJ, Mills G, Macdonald DW 2012. Behavioural adjustments of a large carnivore to access secondary prey in a human-dominated landscape. Journal of Applied Ecology, 49: 7381.

Vucetich JA, Bruskotter JT, Nelson MP 2015. Evaluating whether nature's intrinsic value is an axiom of or anathema to conservation. Conservation Biology, $1-12$.

Wikramanayake E, Dinerstein E, Seidensticker J, Lumpkin S, Panday B et al. 2011. A landscape-based conservation strategy to double the wild tiger population. Conservation Letters, 4: 219-227.

Woodhouse E, Mills MA, McGowan PJK, Milner-Gulland EJ 2015. Religious relationships with the environment in a Tibetan rural community: Interactions and contrasts with popular notions of indigenous environmentalism. Human Ecology, 43: 295-307.

Yirga G, De Iongh HH, Leirs H, Gebrihiwot K, Deckers J, Bauer H 2012. Adaptability of large carnivores to changing anthropogenic food sources: Diet change of spotted hyena (Crocuta crocuta) during Christian fasting period in northern Ethiopia. Journal of Animal Ecology, 81: 1052-1055.

Yirga G, Imama E, De Iongh HH, Leirsc H, Kirosa S et al. 2014. Local spotted hyena abundance and community tolerance of depredation in human-dominated landscapes in Northern Ethiopia. Elsevier, 79(5): 325-330. 